\title{
MOTIVASI MASYARAKAT TERHADAP PENGELOLAAN KHDTK MUNGKU BARU, PALANGKA RAYA
}

\section{COMMUNITY MOTIVATION TO MANAGEMENT OF THE MUNGKU BARU KHDTK, PALANGKA RAYA}

\section{Ardiyansyah \\ Purnamal \\ Ise Afitah ${ }^{2}$ \\ 1,2Universitas \\ Muhammadiyah \\ Palangka Raya, \\ Indonesia}

\section{Kata Kunci: \\ Hutan, Masyarakat, \\ Mungku Baru, Motivasi \\ Keywords: \\ Forest, Local Community, \\ Mungku Baru, Motivation \\ Accepted \\ Maret 2021}

\begin{abstract}
Abstrak
Kawasan Hutan dengan Tujuan Khusus (KHDTK) Mungku Baru merupakan kawasan hutan yang berada di wilayah kota Palangka Raya. KHDTK ini difungsikan sebagai kawasan yang memberi nilai ekonomi dan ekologi yang sangat tinggi untuk meningkatkan kualitas hidup masyarakat dari nilai ekonomi kawasan sebagai daerah penghasil ikan, damar, getah karet, dan hasil hutan bukan kayu lainnya. Penelitian ini bertujuan untuk mengetahui motivasi masyarakat dalam kegiatan pengelolaan KHDTK Mungku Baru. Dari hasil penelitian diketahui tingkat motivasi masyarakat Mungku Baru terhadap kegiatan pengelolaan KHDTK Mungku Baru termasuk kategori rendah dengan skor rata-rata 18.56. Faktor yang berpengaruh terhadap motivasi masyarakat yaitu jumlah keluarga, pendidikan, pekerjaan dan penyuluhan.
\end{abstract}

Published

April 2021

\begin{abstract}
The Mungku Baru Forest Area with Special Purpose (KHDTK) is a forest area located in the city of Palangka Raya. The KHDTK functions as an area that provides very high economic and ecological value to improve the quality of life of the community from the economic value of the area as a producing area for fish, resin, rubber latex, and other non-timber forest products. This study aims to determine the motivation of the community in managing the KHDTK Mungku Baru. From the research results, it is known that the level of motivation of the Mungku Baru community towards the management activities of the Mungku Baru KHDTK is in the low category with an average score of 18.56. Factors that influence community motivation are the number of

families, education, work and counseling.
\end{abstract}

(C) 202I The Authors. Published by Institute for Research and Community Services Universitas Muhammadiyah Palangkaraya. This is Open Access article under the CC-BY-SA License (http://creativecommons.org/licenses/by-sa/4.0/).

\section{PENDAHULUAN}

Kawasan Hutan dengan Tujuan Khusus (KHDTK) Mungku Baru difungsikan sebagai kawasan yang memberi nilai ekonomi dan ekologi yang sangat tinggi untuk meningkatkan kualitas hidup masyarakat dari nilai ekonomi kawasan sebagai daerah penghasil ikan, damar, getah karet, dan hasil hutan bukan kayu lainnya. Dari nilai ekologi kawasan ini merupakan penghasil oksigen serta sebagai kawasan penelitian mahasiswa Fakultas Pertanian dan Kehutanan juga berbagai pihak dalam negeri maupun luar negeri. Dengan luasan \pm 4.910 ha (Empat Ribu Sembilan Ratus Sepuluh Hektar), KHDTK Mungku Baru memiliki beberapa tipe kawasan seperti gambut, kerangas, riparian forest, dan lowland forest dengan tingkat keanekaragaman hayati baik itu vegetasi maupun satwanya yang cukup tinggi.

Untuk pengelolaan KHDTK, UM Palangkaraya juga merangkul masyarakat sekitar KHDTK untuk mengelolanya. Pengelolaan bersama yang dilakukan dengan porsi pengelolaan yang lebih besar diberikan kepada masyarakat sekitar. Untuk mengetahui kebutuhan kebijakan pengelolaan KHDTK yang tepat sasaran diperlukan studi mengenai kondisi masyarakat serta karakteristik yang membentuk perilakunya. Perilaku masyarakat terhadap KHDTK dapat terbentuk dari motivasinya terhadap KHDTK, sehingga untuk mengetahui kebijakan yang tepat sasaran diperlukan data mengenai motivasi dan sikap masyarakat di wilayah tersebut. Motivasi dan sikap masyarakat yang baik terhadap KHDTK dapat dijadikan dasar untuk ikut melibatkan (partisipasi) masyarakat dalam pengelolaan KHDTK, sehingga kondisi KHDTK dapat lebih baik lagi ke depannya dan KHDTK dapat dikelola dengan baik. Dari studi penelitian ini tentunya diharapkan akan menghasilkan luaran berupa informasi baik berupa jurnal ataupun laporan penelitian yang berguna untuk meningkatkan pengelolaan KHDTK. 


\section{Tujuan Penelitian}

Berdasarkan rumusan masalah di atas maka tujuan penelitian ini ialah untuk mengetahui hubungan motivasi masyarakat dalam kegiatan pengelolaan KHDTK Mungku Baru.

\section{METODE PENELITIAN}

\section{Waktu dan Tempat Penelitian}

Lokasi penelitian Motivasi Masyarakat Sekitar terhadap Pengelolaan KHDTK ini berlokasi di Mungku Baru, Kecamatan Rakumpit, Kota Palangka Raya, Provinsi Kalimantan Tengah. Adapun waktu pelaksanaan penelitian ini adalah mulai bulan Juni 2020 sampai dengan bulan September 2020. Dalam jangka waktu tersebut dilakukan pengambilan data lapangan dan pengolahan data, serta analisis data.

\section{Bahan dan Alat Penelitian}

Bahan yang digunakan dalam penelitian ini adalah kuesioner dan data statistik pengembangan KHDTK. Adapun alat yang digunakan dalam penelitian ini antara lain alat tulis, kalkulator, kamera, laptop, software Microsoft Word, software Microsoft Excel, dan software IBM SPSS Statistics 20.

\section{Metode Pengumpulan Data}

a. Metode Penentuan Jumlah Responden

Penentuan responden dilakukan secara Purpossive Sampling, yaitu pengambilan contoh secara sengaja disesuaikan dengan tujuan pengumpulan data, yakni responden yang dapat atau mampu memberi data, informasi, dan penjelasan. Sasaran dari penelitian ini adalah masyarakat yang tinggal di daerah sekitar KHDTK, yakni warga Mungku Baru yang berbatasan langsung dengan wilayah KHDTK. Jumlah responden yang diwawancarai secara keseluruhan ditetapkan berdasarkan rumus dari metode Slovin (Sevilla et. al. 2007), sebagai berikut :

$$
n=\frac{N}{1+(N)\left(e^{2}\right)}
$$

Keterangan:

$\mathrm{n}=$ Jumlah Sampel

$\mathrm{N}=$ Jumlah Populasi

e $=$ Batas Toleransi

Kesalahan (10\%)

b. Jenis Data yang Dikumpulkan

Data-data yang diambil untuk mengetahui motivasi masyarakat sekitar dalam pengelolaan KHDTK diantaranya :

I. Data Primer yang didapatkan dengan cara pembagian kuesioner yang terdiri dari data identitas responden, meliputi nama, umur, pendidikan, pekerjaan, jumlah anggota keluarga, dan lama tinggal. Data wawancara dengan masyarakat sekitar dan pihak-pihak pengelola dari instansi terkait.

2. Data sekunder yang didapatkan dari instansi terkait dengan penelitian dan studi pustaka

c. Uji Validitas dan Realibilitas Kuisioner

Uji Validitas dimaksudkan dalam menentukan keabsahan dari pertanyaan yang digunakan dalam penelitian ini. Instrumen dikatakan valid apabila nilai korelasi (Spearman Correlation) adalah positif dan nilai probabilitas korelasi [sig.(2-tailed)] < taraf signifikan 0,05. Validitas konstruk dihitung dengan cara mencari korelasi dari masing-masing pertanyaan dengan skor total dengan menggunakan software IBM SPSS Statistics 20.

Adapun uji reliabilitas dimaksudkan untuk mengetahui konsistensi alat ukur dalam mengukur gejala yang sama. Suatu kuesioner dikatakan reliabel jika kuesioner tersebut dapat digunakan berulangulang pada kelompok yang sama dan menghasilkan data yang sama. Uji reliabilitas ini menggunakan metode koefisien Alpha Cronbach pada software IBM SPSS Statistics 20. Jika nilainya positif dan nilainya mendekati I (mempunyai alpha cronbach lebih dari $0,6)$ berarti pengukuran yang digunakan reliabel (tercantum pada Tabel I).

Tabel I. Tingkat realibilitas metode Alpha Cronbach

\begin{tabular}{cc}
\hline Alpha & Tingkat Realibilitas \\
\hline 0,00 s.d 0,20 & Kurang Reliabel \\
0,21 s.d 0,40 & Agak Reliabel \\
0,41 s.d 0,60 & Cukup Reliabel \\
0,61 s.d 0,80 & Reliabel \\
0,81 s.d I,00 & Sangat Reliabel \\
\hline
\end{tabular}

\section{Metode Pengolahan dan Analisis Data}

Pengolahan data dan analisis data pada penelitian ini dibagi ke dalam beberapa bagian, 
sebagai berikut :

I. Kegiatan pengelolaan KHDTK

Kegiatan pengelolaan KHDTK digambarkan secara deskriptif disertai gambar setelah dilakukan pengolahan data dan analisis data yang diperoleh, sehingga didapatkan gambaran terkait sistem pengelolaan dan kegiatan di KHDTK Mungku Baru, Palangka Raya.

pada Tabel 2.
2. Faktor Internal dan Faktor Eksternal

Faktor internal dan faktor eksternal merupakan faktor-faktor yang dapat mempengaruhi masyarakat dalam membentuk persepsi dan sikap untuk memutuskan terkait motivasi masyarakat dalam kegiatan pengelolaan KHDTK. Faktor-faktor tersebut diukur dengan menggunakan skala likert seperti

Tabel 2. Skor dari data karakteristik responden

\begin{tabular}{|c|c|c|c|}
\hline $\begin{array}{c}\text { Nomo } \\
r\end{array}$ & Variabel & Kategori & Skor \\
\hline \multicolumn{4}{|c|}{ Faktor Internal } \\
\hline \multirow{4}{*}{$\mathrm{I}$} & & $<37$ Tahun & 1 \\
\hline & Umur & 37 s.d 53 Tahun & 2 \\
\hline & & $>53$ Tahun & 3 \\
\hline & & $<5$ orang & I \\
\hline \multirow[t]{3}{*}{2} & Jumlah Anggota Keluarga & 4 s.d 7 orang & 2 \\
\hline & & $>7$ orang & 3 \\
\hline & & Tidak Sekolah s.d SD & 1 \\
\hline \multirow[t]{3}{*}{3} & Pendidikan & SMP s.d SMA/SMK & 2 \\
\hline & & Diploma s.d Sarjana & 3 \\
\hline & & Tidak Bekerja & I \\
\hline \multirow[t]{3}{*}{4} & Pekerjaan & Wirausaha & 2 \\
\hline & & Pegawai Negeri/Swasta & 3 \\
\hline & & $<23$ Tahun & I \\
\hline \multirow[t]{2}{*}{5} & Lama Tinggal & 23 s.d 46 Tahun & 2 \\
\hline & & $>46$ Tahun & 3 \\
\hline \multirow{2}{*}{6} & \multirow{2}{*}{ Kelamin } & Perempuan & I \\
\hline & & Laki-laki & 2 \\
\hline \multicolumn{4}{|c|}{ Faktor Eksternal } \\
\hline \multirow{3}{*}{7} & & Tidak Pernah Mendapatkan & 1 \\
\hline & Penyuluhan & Pernah Mendapatkan & 2 \\
\hline & & Sering Mendapatkan & 3 \\
\hline
\end{tabular}

3. Motivasi Masyarakat terkait KHDTK

Motivasi masyarakat terkait KHDTK diukur berdasarkan jumlah skor dari pertanyaan pada kuesioner dengan menggunakan skala likert. Setiap pertanyaan memiliki skor seperti yang tercantum pada Tabel 3. Sikap yang diukur mengenai kesiapan masyarakat untuk berperilaku terhadap KHDTK.

Tabel 3. Skor pertanyaan terkait sikap masyarakat

\begin{tabular}{ccc}
\hline Nomor & Kategori & Skor \\
\hline $\mathrm{I}$ & Setuju & 3 \\
2 & Ragu-ragu & 2 \\
3 & Tidak setuju & $\mathrm{I}$ \\
\hline
\end{tabular}

\section{HASIL DAN PEMBAHASAN}

\section{Karakteristik Responden}

I. Umur Responden
Responden terdiri dari berbagai tingkatan umur. Responden didominasi oleh kelompok umur 
37 sampai 53 tahun yaitu sebesar $41.43 \%$. Umur tersebut berada pada kisaran umur produktif, sesuai dengan pernyataan Muttaqien (2006) bahwa penduduk usia produktif berkisar antara bahwa dapat dilihat pada Gambar I. penduduk usia produktif berkisar antara 15 sampai dengan 65 tahun. Sebaran responden berdasarkan kelas umur

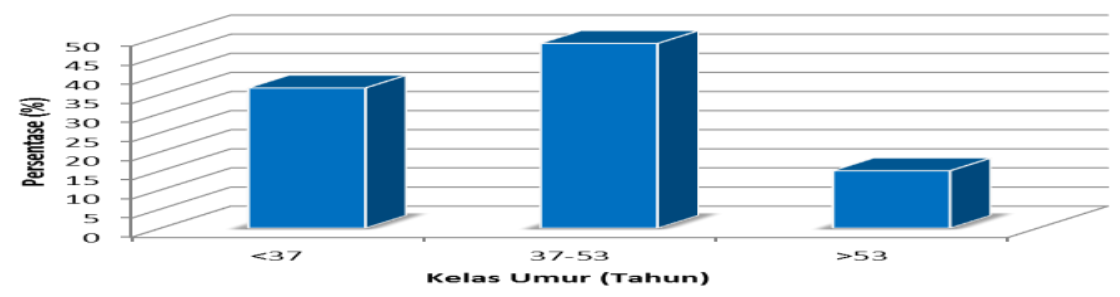

Gambar I. Sebaran Responden Berdasarkan Kelas Umur

2. Jumlah Anggota Keluarga

Karakteristik responden dalam hal jumlah anggota keluarga didominasi oleh responden dengan jumlah anggota keluarga ada pada rentan 4-7 sebesar 56.67\%. Ukuran keluarga menurut Badan Koordinasi Keluarga Berencana Nasional (BKKBN orang. Sebaran responden berdasarkan jumlah anggota keluarga dapat dilihat pada Gambar 2.

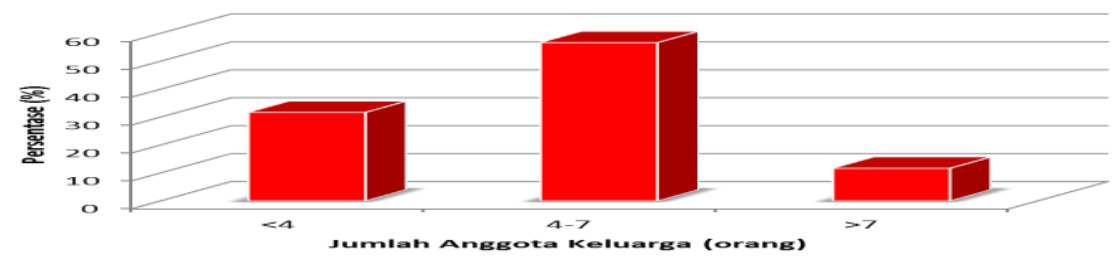

Gambar 2. Sebaran Responden Berdasarkan Jumlah Anggota Keluarga

3. Tingkat Pendidikan Responden

Pendidikan memiliki peranan penting dalam menentukan kualitas sumberdaya manusia serta tingkat kesejahteraan sehingga dapat menjadi

2014) dibagi menjadi tiga kategori, yaitu keluarga kecil ( $\leq 4$ orang), keluarga sedang (5-7 orang), dan keluarga besar ( $\geq 8$ orang). Ukuran keluarga yang dimaksud oleh BKKBN tersebut adalah ukuran keluarga inti yang terdiri atas istri, suami dan anak. Rata-rata jumlah keluarga responden yaitu 4-7

$$
\text { . }
$$




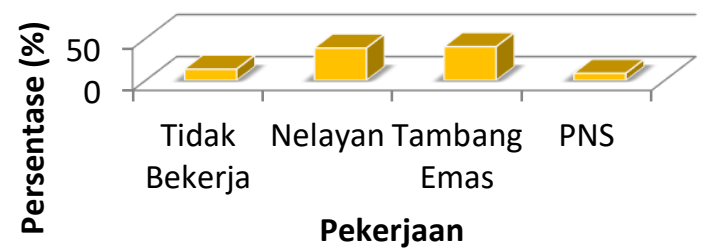

5. Lama Tinggal

Gambar 4. Sebaran Responden Berdasarkan Pekerjaan

Karakteristik responden berdasarkan lama tinggal antara 23-46 tahun yaitu sebesar 32 orang tinggal didominasi oleh responden dengan lama atau $53.33 \%$.

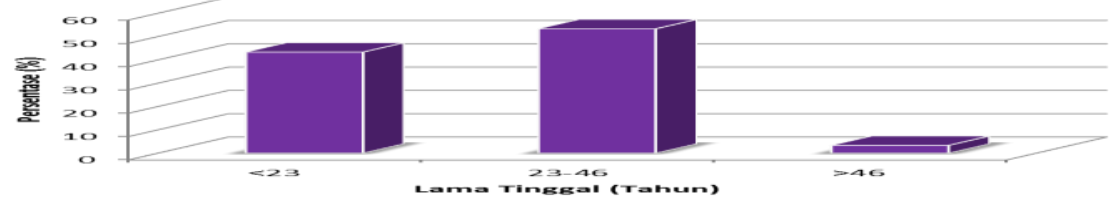

Gambar 5. Sebaran Responden Berdasarkan Lama Tinggal

6. Penyuluhan

Responden yang pernah memperoleh penyuluhan tentang Kawasan Hutan Dengan Tujuan Khusus (KHDTK) Mungku Baru sebanyak 2I orang dengan persentase sebesar 35\%. Sebaran responden mendapatkan penyuluhan dapat dilihat pada Gambar 6.

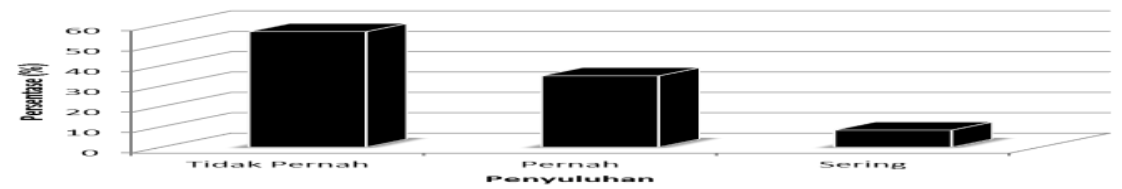

Gambar 6. Sebaran Responden Mendapatkan Penyuluhan

\section{Motivasi Masyarakat}

Motivasi atau motif adalah dorongan yang menggerakan seseorang untuk melakukan sesuatu dalam pemenuhan kebutuhan hidupnya. Motivasi merupakan faktor yang tumbuh dalam diri manusia berupa nilai-nilai yang mendorong untuk mengambil manfaat atau kesempatan. Motivasi masyarakat terhadap Pengelolaan KHDTK Mungku Baru diketahui dari data wawancara terstruktur. Hasil dari pengujian validitas dan reabilitas kemudian di skoring menggunakan skala likert dengan kategori tinggi, sedang dan rendah (Tabel 4).

Tabel 4. Motivasi Masyarakat Terhadap Pengelolaan KHDTK Mungku Baru

\begin{tabular}{cccc}
\hline Nilai Motivasi & Jumlah (Orang) & Persentase (\%) & Kategori \\
\hline $29-36$ & 19 & 31,67 & Tinggi \\
$21-28$ & 13 & 21,67 & Sedang \\
$12-20$ & 28 & 46,67 & Rendah \\
\hline I8,56 & 60 & 100 & Rendah \\
\hline $\begin{array}{l}\text { Motivasi masyarakat Mungku Baru keseluruhan } \\
\text { terhadap pengelolaan KHDTK termasuk dalam }\end{array}$ & KHDTK yang dimiliki masyarakat Mungku Baru \\
kategori rendah dengan skor 18.56. Hasil analisis & masih rendah. Rendahnya tingkat motivasi \\
menunjukkan bahwa tingkat motivasi masyarakat & masyarakat Mungku Baru antara lain disebabkan \\
tergolong rendah dengan persentasi sebesar 46.67 & \multicolumn{2}{c}{ oleh tidak termotivasinya masyarakat setempat } \\
\%, kemudian presentasi tinggi sebesar 31.67\% dan & untuk mengelola kawasan hutan disekitarnya.
\end{tabular}

\section{Faktor Yang Mempengaruhi Motivasi Masyarakat}

Tabel 5. Faktor yang Mempengaruhi Motivasi Masyarakat 


\begin{tabular}{lc}
\hline Umur & 0,131 \\
Jumlah Anggota Keluarga & $0,274^{*}$ \\
Pendidikan & $0,249^{*}$ \\
Pekerjaan & $0,367^{*}$ \\
Lama Tinggal & 0,108 \\
Penyuluhan & $0,699^{* *}$ \\
\hline
\end{tabular}

*: Correlation is significant at the 0.05 level (2-tailed)

** : Correlation is significant at the 0.01 level (2-tailed)

Berdasarkan tabel di atas faktor yang

DAFTAR PUSTAKA

berpengaruh nyata terhadap motivasi masyarakatArief, A. 1994. Hutan (Hakekat dan Pengaruhnya Terhadap dalam pengelolaan KHDTK Mungku Baru di Lingkungan). Jakarta: (ID) Yayasan Obor Indonesia. antaranya adalah; faktor pekerjaan sebesar 0.367, [BKKKBN] Badan Koordinasi Keluarga Berencana Nasional. faktor jumlah anggota keluarga sebesar 0.274 dan faktor pendidikan sebesar 0.249. Adapun yang berpengaruh sangat nyata terhadap motivasi masyarakat adalah faktor penyuluhan sebesar 0.699 .

Dalam kajian pelibatan masyarakat terhadap kegiatan pengelolaan KHDTK perlu mempertimbangkan kebutuhan, aspirasi, dan pengalaman masyarakat yang ditujukan untuk meningkatkan kesejahteraan bersama sehingga manfaat yang diperoleh dari kebijakan tersebut terbagi adil bagi masyarakat, serta turut meningkatkan status sosial masyarakat. Pelibatan masyarakat dalam kegiatan pengelolaan KHDTK dapat berupa penyediaan dan pemanfaatan sebagian areal hutan KHDTK sebagai tempat budidaya yang dikelola masyarakat Mungku Baru. Selain itu perlu dilakukan kajian mengenai perilaku masyarakat sekitar terhadap pengelolaan hutan KHDTK.

\section{KESIMPULAN DAN SARAN}

\section{Kesimpulan}

Motivasi masyarakat Mungku Baru terhadap kegiatan pengelolaan KHDTK Mungku Baru termasuk kategori rendah dengan skor rata-rataMuttaqien A. 2006. Paradigma Baru Pemberantasan 18.56. Faktor yang berpengaruh terhadap motivasi masyarakat yaitu jumlah keluarga, pendidikan, pekerjaan dan penyuluhan.

\section{Saran}

Perlu dilakukan strategi peningkatan motivasi masyarakat terhadap pengelolaan KHDTK guna meningkatkan dan memperbaiki perilaku masyarakatMursidin. Mungku Baru agar lebih peduli akan kondisi hutan di KHDTK, strategi tersebut dapat berupa peningkatan penyuluhan mengenai hutan gambut, kerangas, riparian forest, dan lowland forest. 2014. Opini Pembangunan Keluarga Berencana. Jakarta (ID): BKKBN.

Budiarti, S. 20II. Persepsi dan Partisipasi Masyarakat Desa Sekitar Hutan terhadap Sistem PHBM di Perum Perhutani (kasus di KPH Cianjur Perum Perhutani Unit III, Jawa Barat) [Skripsi]. Bogor (ID): Departemen Manajemen Hutan. Institut Pertanian Bogor

[Depdikbud] Departemen Pendidikan dan Kebudayaan (ID). 1998. Kamus Besar bahasa Indonesia. Jakarta (ID): Balai Pustaka.

Fitriadi, Gunawan T, Rijanta. 2005. Peran Pemerintah dan Partisipasi Masyarakat dalam Rehabilitasi Hutan Mangrove: kasus di Kecamatan Pemangkat Kabupaten Sambas Kalimantan Barat. Manusia dan Lingkungan. 12(3): I22-129.

[Kemenhut] Kementerian Kehutanan (ID). 20II4. SK Menteri Kehutanan Nomor 6II/Menhut-II/20I4 tetang Penetapan Kawasan Hutan dengan Tujuan Khusus sebagai Hutan Pendidikan pada Kawasan Hutan Produksi Tetap di Kota Palangka Raya, Provinsi Kalimantan Tengah seluas $4.910 \mathrm{Ha}$.

Kemiskinan: Rekontruksi Arah Pembangunan Menuju Masyarakat yang Berkeadilan, Terbebaskan dan Demokratis. Di Dalam: Raharjo Dawam, penyunting. Menuju Indonesia Sejahtera: Upaya Konkret Pengentasan Kemiskinan. Jakarta: Khanata, Pustaka LP3ES Indonesia. hlm. 3-43.

2009. Peran Gender dalam Kehidupan Keluarga Hubungan dengan Tingkat Kesejahteraan Masyarakat. Di dalam: Nasution Zahri dan Hikmah, penyunting. Dinamika peran gender dan disemasi inovasi. Jakarta(ID): Badan Riset Kelautan dan Perikanan. 
Ardiyansyah Purnama dan Ise Afitah. Motivasi Masyarakat Terhadap Pengelolaan Khdtk Mungku Baru, Palangka Raya

Rakhmat J. 20II. Psikologi Komunikasi. Bandung (ID): PT. Wicaksono AM. 20I0. Analisis Tingkat Partisipasi Warga Rermaja Rosdakarya.

Sevilla CG. et. al. 2007. Research Methods. Quezon City $(\mathrm{PH})$ : Rex Printing Company.

Suharjito D, Darusman D. 1998. Kehutanan Masyarakat: Beragam Pola Partisipasi Masyarakat. Bogor (ID): Proyek Kerjasama Institut Pertanian Bogor dan The Ford Foundation. dalam Tanggung Jawab Sosial Perusahaan (Studi Kasus PT Isuzu Astra Motor Indonesia Assy Plant Pondok Ungu). Skripsi. Bogor (ID): Institut Pertanian Bogor.

Zainun B. 1989. Manajemen dan Motivasi. Jakarta (ID): Balai Aksara. 